\title{
Sustainable Hospital Architecture - Potential of Underground Spaces
}

\author{
Irina Bulakh ${ }^{1, *}$, Iryna Merylova ${ }^{2}$ \\ ${ }^{1}$ Department of Design Architectural Environment, Kyiv National University of Construction and Architecture, Kyiv, Ukraine \\ ${ }^{2}$ Department of Architectural and Urban Planning, State Higher Education Establishment "Pridneprovsk State Academy of Civil \\ Engineering and Architecture", Dnipro, Ukraine
}

Received September 10, 2020; Revised October 19, 2020; Accepted October 25, 2020

\section{Cite This Paper in the following Citation Styles}

(a): [1] Irina Bulakh, Iryna Merylova , "Sustainable Hospital Architecture - Potential of Underground Spaces," Civil Engineering and Architecture, Vol. 8, No. 5, pp. 1127 - 1135, 2020. DOI: 10.13189/cea.2020.080539.

(b): Irina Bulakh, Iryna Merylova (2020). Sustainable Hospital Architecture - Potential of Underground Spaces. Civil Engineering and Architecture, 8(5), 1127 - 1135. DOI: 10.13189/cea.2020.080539.

Copyright $\subseteq 2020$ by authors, all rights reserved. Authors agree that this article remains permanently open access under the terms of the Creative Commons Attribution License 4.0 International License

\begin{abstract}
The article is a part of the study devoted to the urban planning of healthcare system spatial development, hospitals in particular. The research is based on systemic and integrated analysis. A number of case studies are provided. The article addresses topical issues of possible ways to improve environmental friendliness, energy efficiency and harmonization with the natural and artificial environment of health care facilities, which will contribute together to a sustainable vector of architectural development. One of the newest and most promising ways of architectural development of medical institutions is associated with the active integration of the potential use of underground space into the design of hospitals. The article considers the best experience of designing hospital buildings in which the underground space performs various functions, as well as a number of practical techniques aimed at balancing the uncomfortable feeling of "underground" of the premises located in the basement. The following progressive directions of using underground spaces in the design of modern hospitals have been identified, described and analyzed: underground location of rooms for patients, staff and technical purposes. The proposed approach allows: reduction of the perimeter of a building, which interacts with changing climatic conditions; natural stable temperature; potential use of different types of heat pumps as a "green" means of increasing heat energy (soil, ambient air and groundwater); noise reduction from the environment; using the area of the entire land plot with a significant underground extension.
\end{abstract}

Keywords Architecture and Urban Planning,
Underground Space, Hospital Design, Atrium, Courtyard, Hospital Energy Efficiency

\section{Introduction}

The events of the last six months have forced the entire civilized world to pay attention to the quality and efficiency of healthcare. In all countries medical sector experienced quite significant difficulties - there was a lack of equipment and places in hospitals, many countries were forced to deploy temporary hospitals for the daily admission of a large number of patients who had no chance of recovery in outpatient treatment. This "shock therapy" and a harsh natural reminder of the value and vulnerability of human life and health, we hope in the near future, will lead to international and national programs for the development, expansion and modernization of healthcare and one of its key elements - hospitals, in particular.

Modern hospitals are complex multidisciplinary medical facilities that require a lot of space to accommodate various components of the units. This can be achieved in several ways such as the design of multi-storey buildings, medium-rise buildings in large urban areas, etc. Each of these areas has positive and negative features and is selected in accordance with the specific urban context and opportunities. In case of construction of a new hospital or a current medical building extension in the existing urban environment, a solution to build a multi-storey hospital is 
often chosen.

However, there may be a number of limitations and conflicts within the urban context: required height for sufficient hospital space and the height of historic buildings; design and construction restrictions as for the height of buildings according to the state regulations in some countries; complicating the formation of artistic and aesthetic image of a hospital, which would create a psychological feeling of peace and confidence in patients.

Taking into account these aspects, construction of a new hospital in a large urban area can take place only on the outskirts of the settlement or outside it. This article, as an alternative and innovative way of architectural design of hospitals, which avoids the problems and issues of preventing high-rise or free and expansive construction of a hospital building in large urban areas, proposes an approach related to partial integration of medical buildings into underground space. In addition to the already mentioned positive features, it is important that this project approach also deals with the potential of underground space in terms of sustainable development of architecture and healthcare sector, in particular.

The research questions in this article are as follows: an ecological and sustainable development approach to the architecture of medical buildings, the aspect of human perception of the underground space, sustainable development of the architecture of healthcare facilities by the example of the latest experience of leading countries in the medical field. Thus, space, sustainability and therapeutic effects are the main issues.

\section{Literature Review}

Research of underground space and the peculiarities of its use in the design of hospitals was partially carried out in the book Urban Underground Space Designing China: Vernacular and Modern Practice [1]. This study was the first to be presented in English to outline and illustrate China's experience in designing and using underground non-residential public facilities, including the architecture of hotels, hospitals, theaters and shopping malls. The main emphasis in the study is to put on the location of technical and auxiliary hospital facilities on one underground floor. It is necessary to mention that over the period of 30 years, after this book was published, a lot has changed - new building materials have appeared, building technologies have improved [2], [3]. Nowadays, the issues of high operating costs and the lack of free land resources are significantly relevant. Thus, this book in the article is considered from the point of view of the first publication, because it touched on the topic of underground space of hospitals but, of course, does not provide answers to all questions.

The investigations concerning traditional and historical experience of construction of underground city structures in architecture on the basis of sustainable development of urban environment are also analyzed [4]. It was important to refer to national and historic experience of Iran, where underground spaced was traditionally created in urban environment. Returning to the architectural heritage of the past is also quite appropriate in the XXI century in connection with a new vector of civilized society development, which is based on environmental principles of sustainable development, energy savings and effective ways to reduce energy consumption in urban areas. An ecological and sustainable development approach to architecture of medical buildings is one of the key issues in this study, which describes historical experience and modern advances. Problems of the sustainable development of urban environment today are widely considered in many countries. Numerous symposia and conferences are held in this direction.

Also, the article is based on the research of I. Merylova and $\mathrm{K}$. Sokolova in the field of cognitive approach to urban studies "A human in the urban space of the globalized world" (2020). The aspect of human perception of the underground space and psychological feeling of a human in it were considered. This topic is also one of the issues of the presented study about the architecture of medical buildings. The results obtained are briefly described in this article. This article uses the findings of the study devoted to the influence of architecture on a psychological state of a human, which are partially described in scientific articles and conference papers [5], [6].

The papers of the participants of The International Conference on Sustainable Futures: Environmental, Technological, Social, and Economic Matters (held at Kryvyi Rih National University, Kryvyi Rih, Ukraine, on May 20-22, 2020) were analyzed in the current article. At the conference, scientists from various scientific fields raised a number of issues with regard to geotechnical and geoenvironmental engineering, sustainable mining, sustainable construction and architecture, sustainable cities and society, sustainable materials and technologies, sustainable transport, sustainable energy, measuring, sustainability forecasting and monitoring [7]. It is noteworthy that the conference also addressed the issues of sustainable development of the architecture of healthcare facilities by the example of the latest experience of leading countries in the medical field [8]. The problems of sustainable and ecological approaches to architectural design of hospitals are raised in the research [8]. The best international experience of designing and operating hospitals based on the principles of sustainable development is considered. Examples and implementation experience of energy efficient technologies in healthcare institutions are analyzed and illustrated: natural ventilation, solar panels, rainwater collection, filtration and reuse of wastewater, providing green spaces on the roof and walls, sun protection, aerodynamic volumetric and spatial form. Studying and using the proven experience of the best 
examples of ecological hospital buildings, recognized and certified at the highest levels of the world institutions for the development of sustainable future, will allow Ukraine to create the conditions for solving the crisis both in the sphere of healthcare and in the ecologically preserved environment of the country.

This article is a part of a comprehensive study of urban planning foundations of territorial and spatial development of the system of children's medical complexes, which is conducted within the doctoral research in the field of architecture and urban planning. The article is an ecological and natural continuation of a number of scientific works [9], [10], [11] on the way to find the latest theoretical and practical tools, methods and techniques in order to improve the quality and efficiency of architectural and urban planning solutions in architectural and urban planning design of various healthcare facilities. The article gives an overview of the existing literature on the research topic, and also offers case studies provided by the authors of the article.

\section{Global Experience in the Design and Use of Underground Hospital Environment}

Traditionally, in many countries around the world, when designing hospitals, the underground space was used as one floor and provided as a technical basement. This project approach was caused due to the need to quantify and expand the urban network of healthcare facilities, as well as due to a number of the following factors: focus on design and construction of typical projects in order to save time and money; use of economic construction and industrial methods and approaches; lack of understanding about energy crisis consequences and, as a result, failure to follow energy savings, search and integration of energy efficient technologies and solutions. In the post-Soviet countries, in particular in Ukraine, the underground (basement) spaces of healthcare facilities are in terrible condition, although they serve as technical premises (Fig.1, Fig.2).
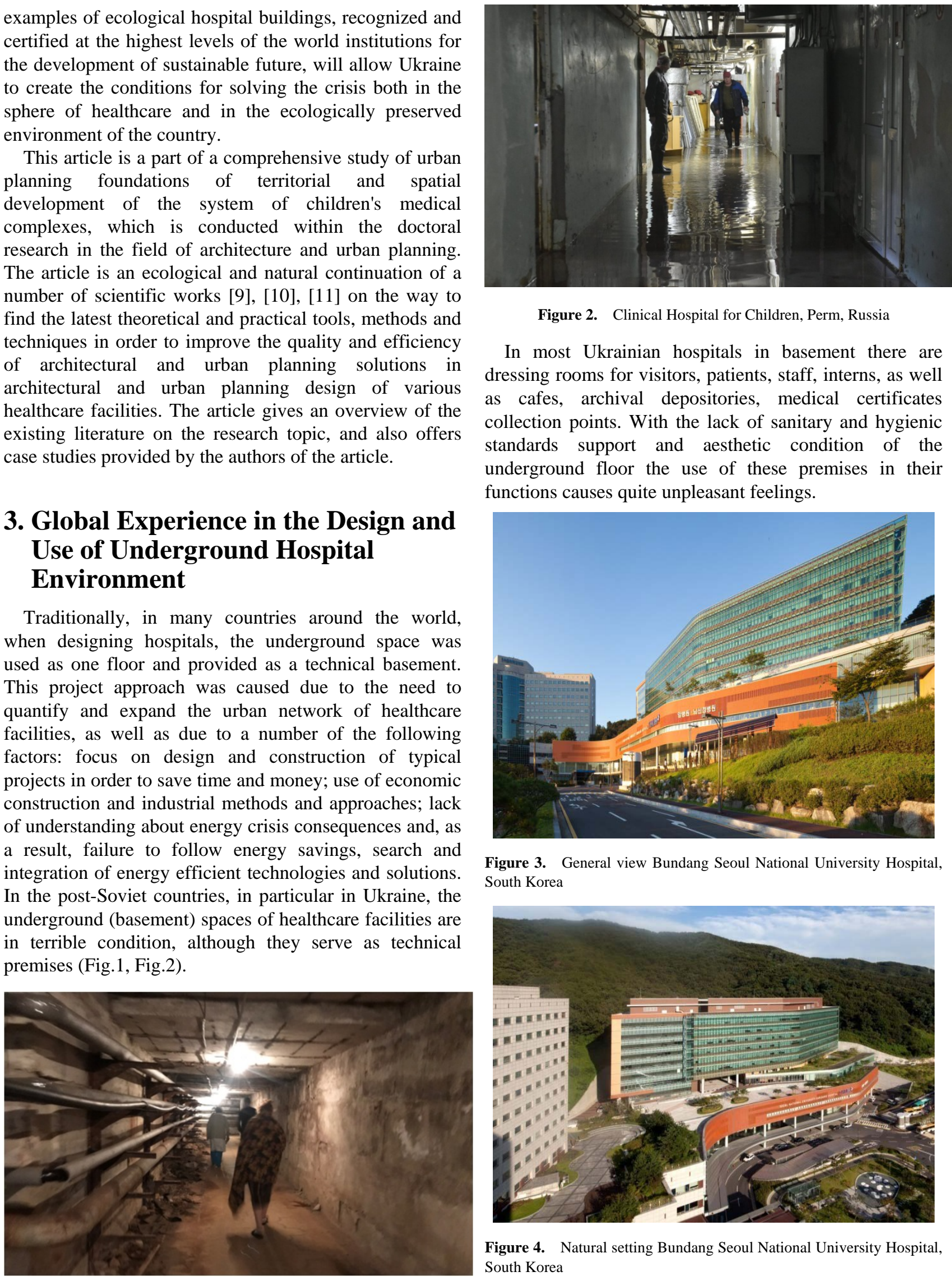

Figure 2. Clinical Hospital for Children, Perm, Russia

In most Ukrainian hospitals in basement there are dressing rooms for visitors, patients, staff, interns, as well as cafes, archival depositories, medical certificates collection points. With the lack of sanitary and hygienic standards support and aesthetic condition of the underground floor the use of these premises in their functions causes quite unpleasant feelings.

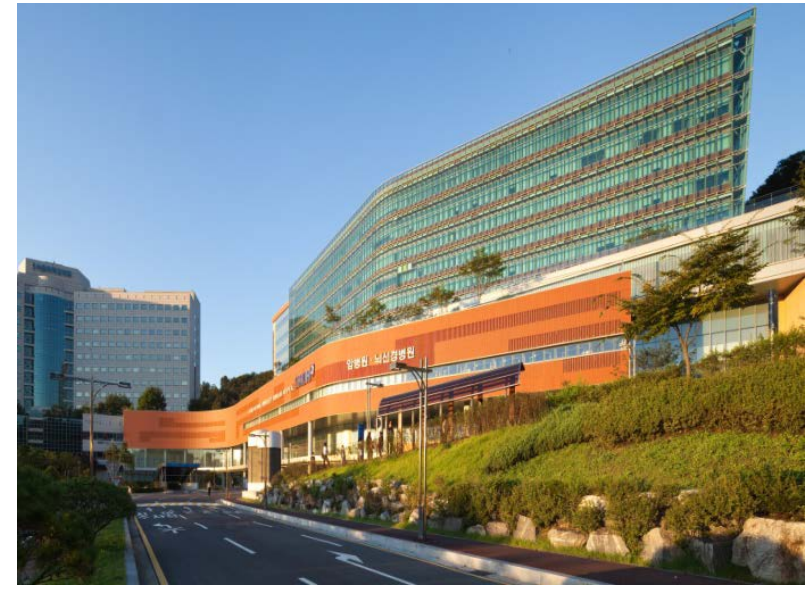

Figure 3. General view Bundang Seoul National University Hospital, South Korea

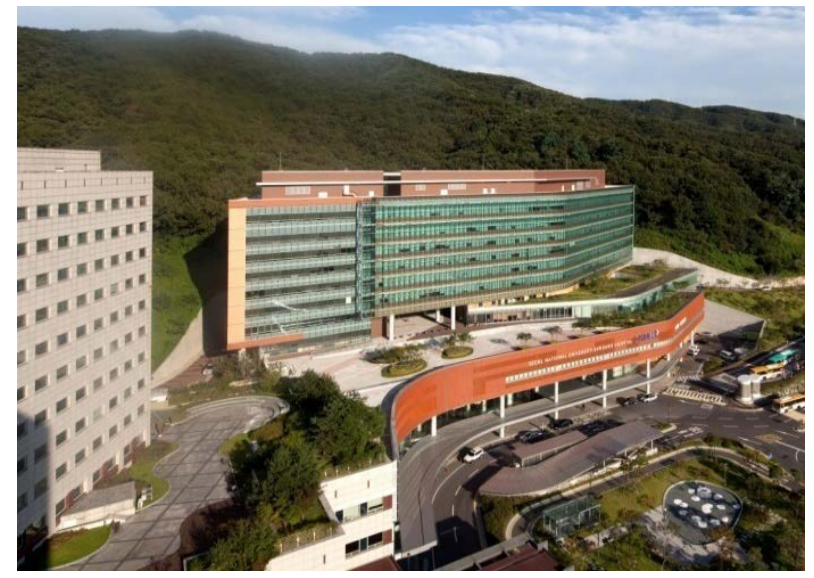

Figure 4. Natural setting Bundang Seoul National University Hospital, South Korea

Figure 1. Kyiv City Clinical Hospital №4, Kyiv, Ukraine

Along with the outlined negative, inexpedient and 
inappropriate experience of underground hospital space application, there is another approach that corresponds to the rational and environmental aspects of sustainable development of architecture of medical institutions. A similar modern example is the project of Bundang Seoul National University Hospital by JUNGLIM Architecture. Established in 2003, Bundang Seoul National University Hospital is located in a metropolitan area with a good natural environment adjacent to Bulgok Mountain and Tancheon (Fig. 3, Fig. 4). This picturesque natural environment caused some difficulties in 2009, when it was decided to expand the area of the hospital.

Changes in topography of the area for a new hospital construction made the architects look for compromises that would allow building a new hospital of the required size but still adjacent to the existing building and with natural insolation of stationary wards [12]. Among many search options, the architects managed to find a solution that allowed to harmoniously connect a new building with natural context, as well as with the existing hospital building. To achieve this result, a new 15-storey hospital building was developed underground - taking into account natural terrain, the architects placed from three to six floors underground (Fig. 5, Fig.6) [12].

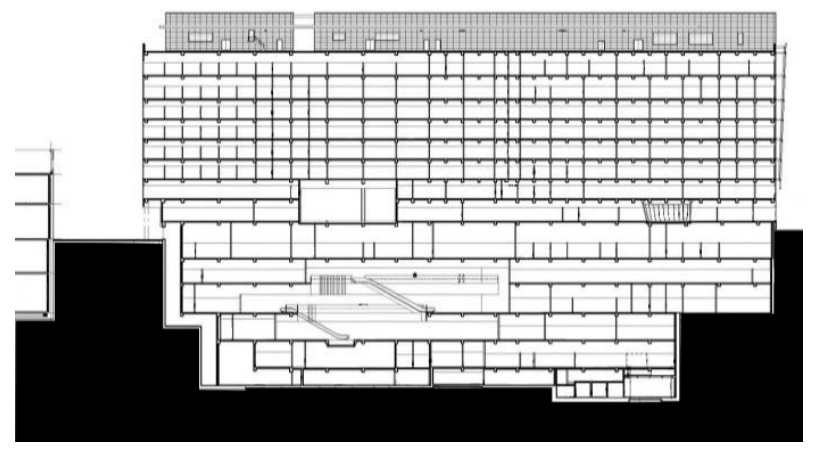

Figure 5. Sectional drawing Bundang Seoul National University Hospital, South Korea

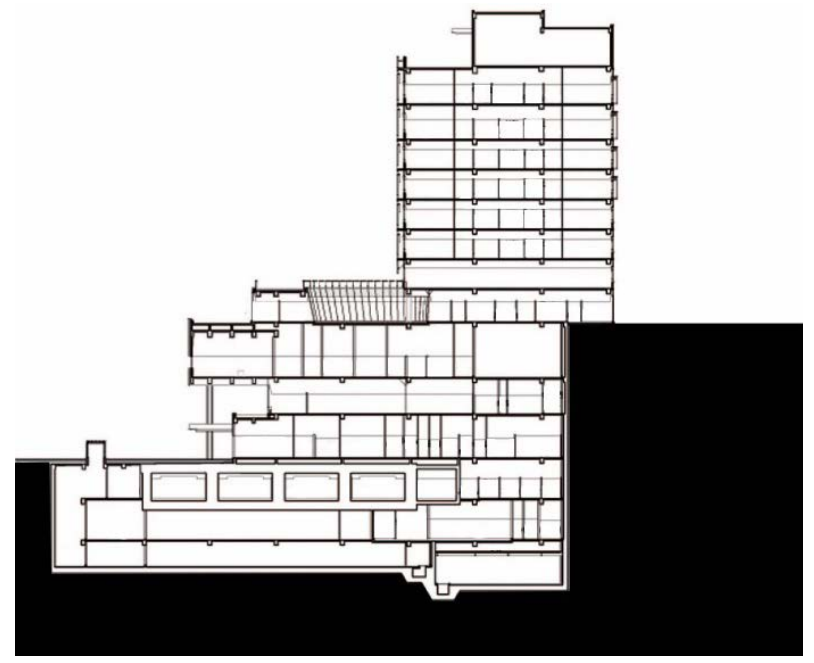

Figure 6. Cross-sectional drawing Bundang Seoul National University Hospital, South Korea
Most of the underground rooms were provided with natural light due to a number of techniques - anti-aircraft lights, linear two- and three-storey atriums, glass partitions, etc. As a result, the architects managed to eliminate the uncomfortable feeling of "undergroundness", which is usually caused in a room without natural light and visual contact with the environment.

The use of underground space in the construction of a hospital due to the hilly terrain can also be found in the project of The Sieff Hospital, designed by Weinstein Vaadia Architects in 2016 in Israel. The area for the design of the hospital, in addition to its topography, was also quite compact. Consequently, a significant part of the hospital building was integrated into the terrain, obtaining a practical underground location. To maximize the lighting of doctors' offices and other office space planned by the architects in the hospital's underground area, the project provides an open enclosed courtyard, which also opens up additional views of the landscape architecture in miniature (Fig. 7) [13].

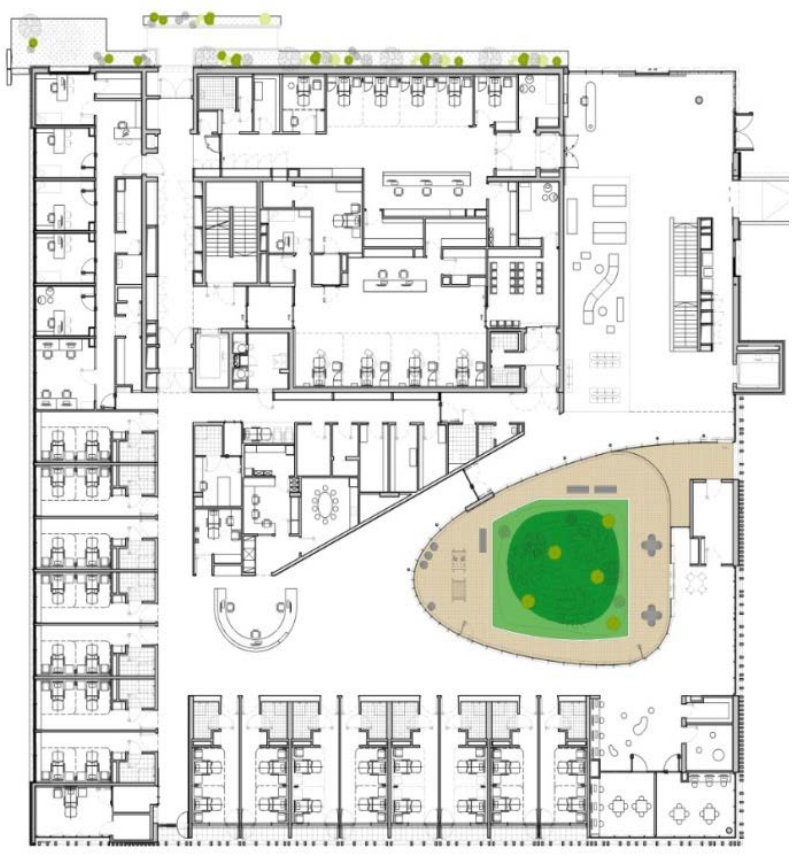

Figure 7. General layout and cross section of The Sieff Hospital, Israel

The next visualization of rational underground space is Pars Hospital, a project implemented by New Wave Architecture company in 2016 in Iran. In this example, there is only one underground floor for technical use (parking for service vehicles, staff and patients), but it allowed them to 'relieve' the street and hospital territory from parking cars, which is very important for healthcare facilities in a dense urban environment (Fig. 8) [14]. Thus, Pars Hospital showed one of possible ways how to use underground hospital space for parking. 

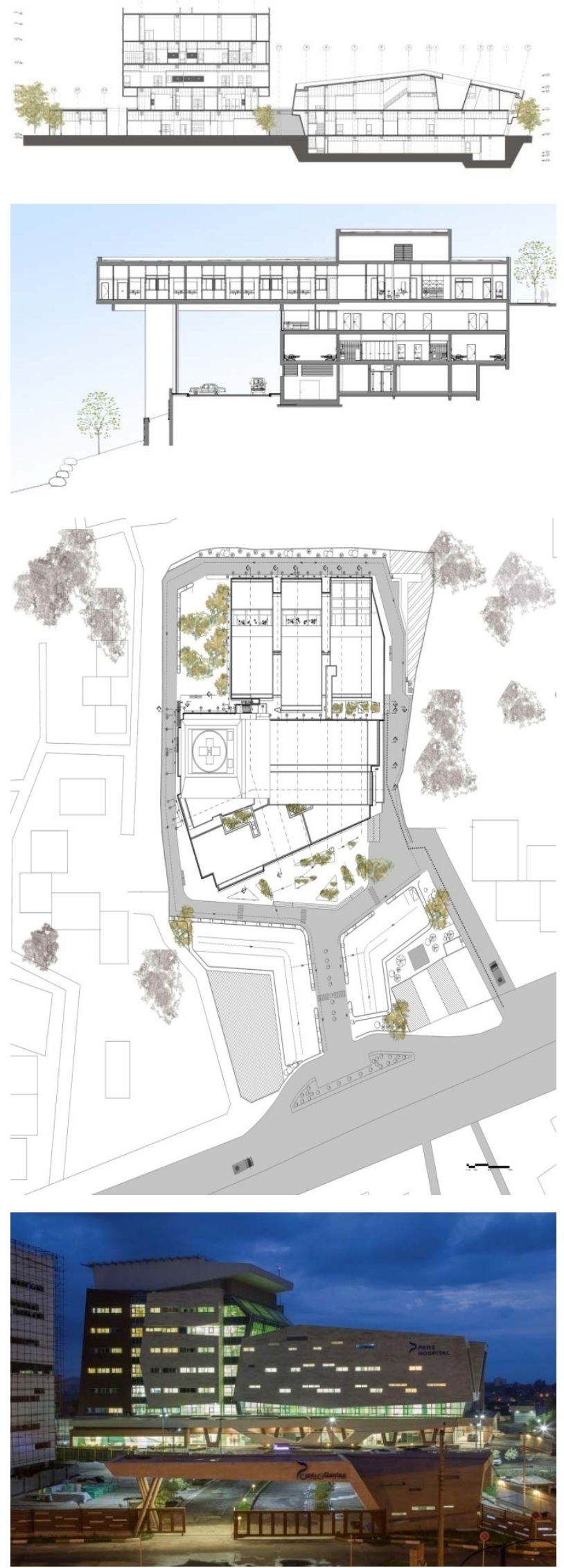

Figure 8. General layout and cross section of Pars Hospital, Iran
The project of New Hospital Tower Rush University Medical Center, designed by Perkins + Will company and built in Chicago, United States in 2012 is of some interest in this research. The project is attractive not only by a single underground floor for technical purposes, but also by its design technique - a number of small inclusive atriums (Fig. 9) [15]. The whole architectural idea made possible to solve certain tasks: to provide middle of the building with natural lighting, to create interesting public space with landscape "integration" of nature, to give this medical facility some individual features and aesthetics. Such approach could be suggested in the design of an underground medical environment - integrated "perforation" of some underground levels, which can be exposed to natural light and comfortable atmosphere.
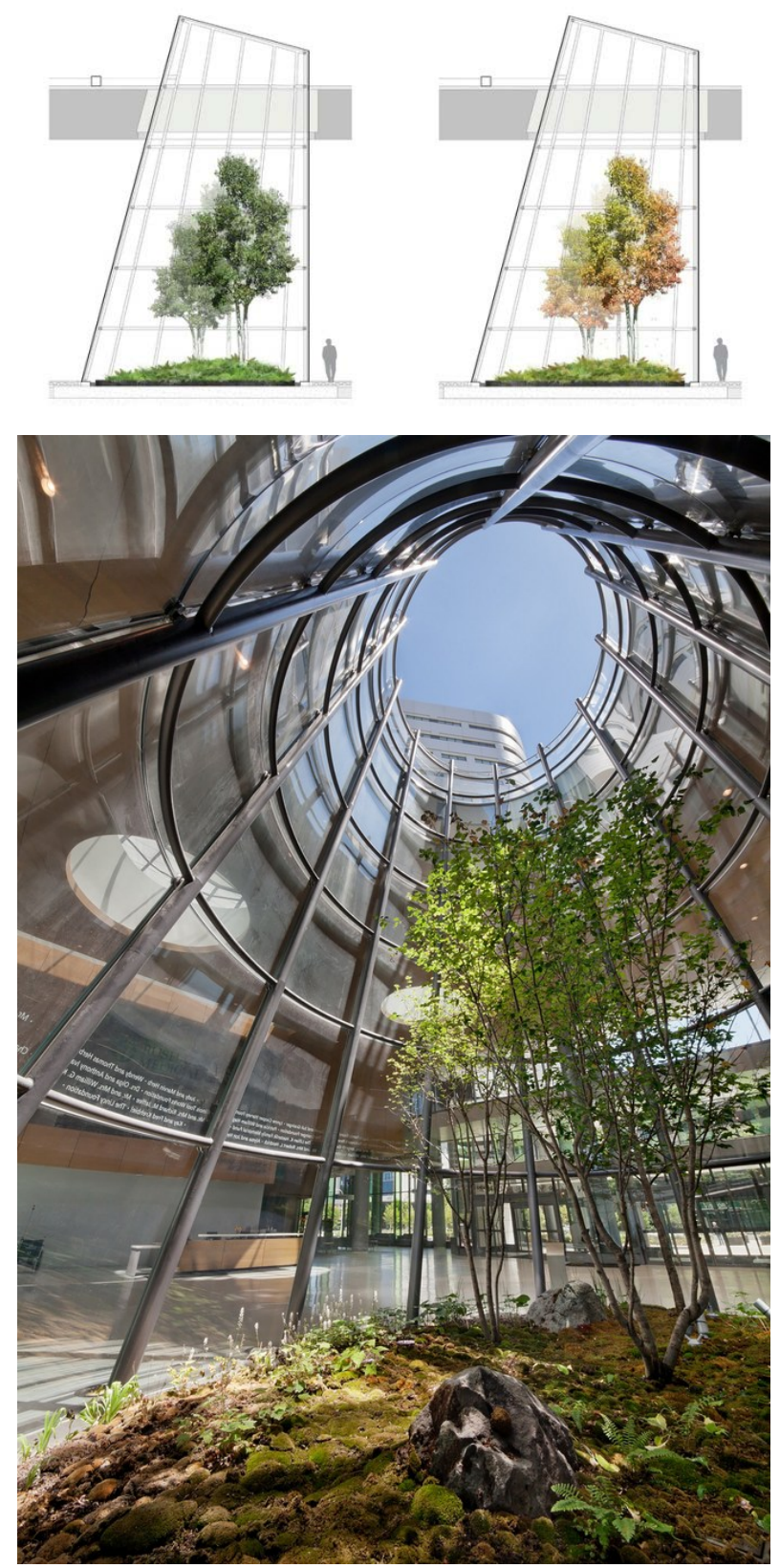


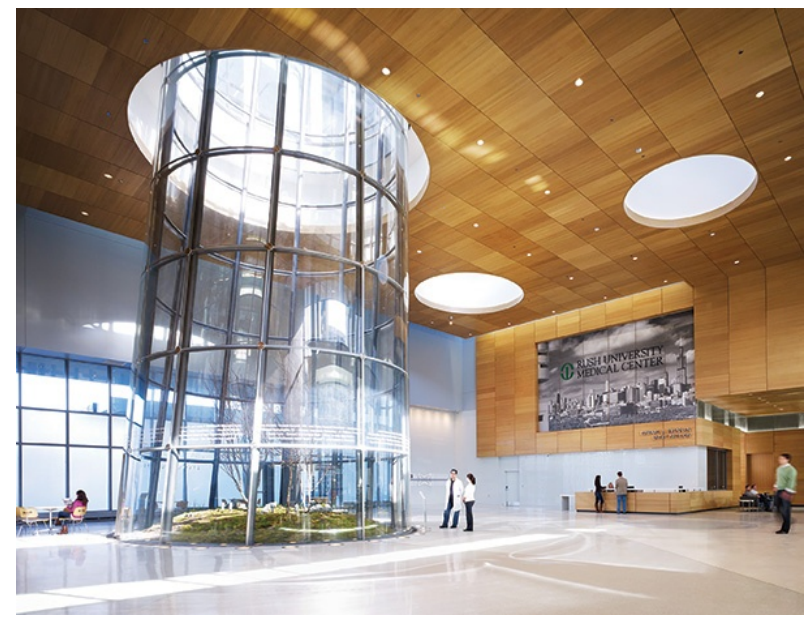

Figure 9. "Nature capsules" in New Hospital Tower Rush University Medical Center Chicago, United States
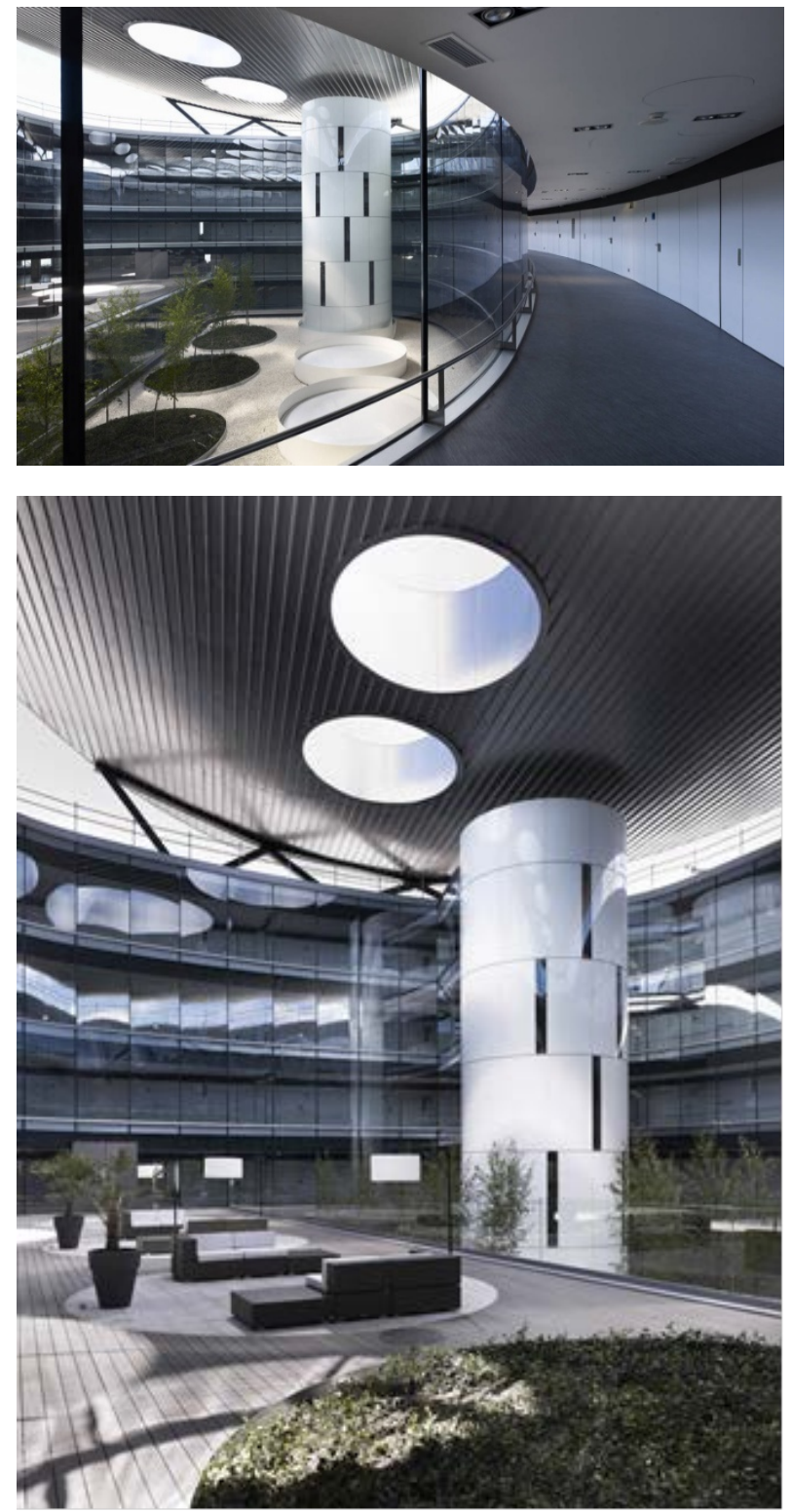

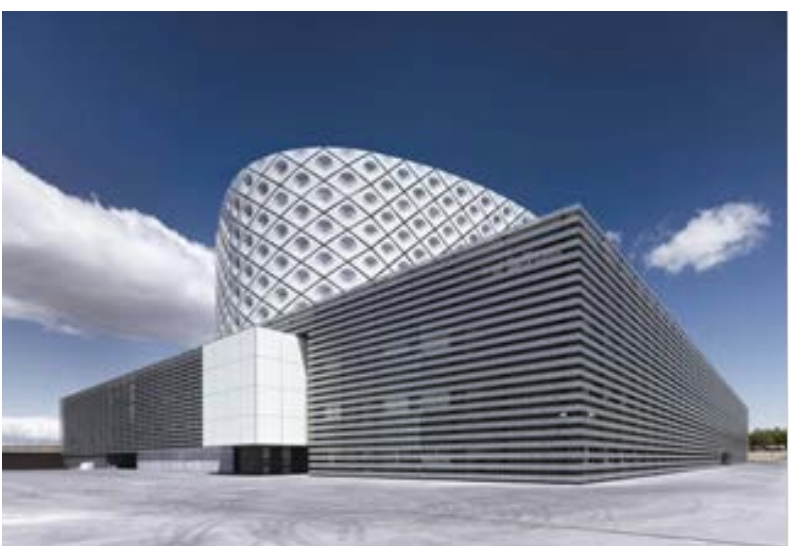

Figure 10. Rey Juan Carlos Hospital, Madrid, Spain

Rey Juan Carlos Hospital project, by Rafaelde La-Hozy 2012, Madrid, Spain is one more to consider. The concept of this hospital project provided for the interaction of three main components: efficiency of process organization, light and silence. The architect also tried to combine the best achievements of hospital and residential architecture to obtain a new synthetic model of medical space. A special role in this model is given to the architecture of medical environment, where natural light and silence cause a therapeutic effect - "the use of architecture as a medical treatment". One of the main points in a building is sustainability - considering conditions of solar orientation, topography, building and green environment around in terms of urban conditions, as well as incorporated green materials and renewable energy technology to save resources and operating costs (for instance, green roof, natural light and ventilation inside the building). This general comment is of direct relevance to the purpose of this article - to show an integrated approach to sustainable hospital architecture, the component of which is to use the potential of underground spaces. The hospital also has an underground floor, but the whole building is built as if it is concealed from the environment - this technique and the effect of artificial illusion of "immersion" of the ground-based building in the underground space is associated with an attempt to create a special atmosphere with dimmed and controlled lighting and minimization of external and internal noise (Fig. 10) [16].

In terms of exploring the potential use of underground spaces in the design and construction of health facilities, the design experience of the Hospital of Sant Joan Despi Doctor Moises Broggi, jointly developed in 2010 by Pinearq + Brullet-De Luna Arquitectes team in Sant Joan Despí, Spain, is extremely valuable. Its non-standard and individual solution is based on elongated proportions of the construction site, as well as the architect's efforts to clearly distinguish all functions and human flows (visitors, inpatients and outpatients, medical center, emergency medical service, staff, etc.). All the main functions, according to the architects, should be autonomous, leaving the possibility for a clear orientation of visitors and 
patients due to the constant relationship between external environment and interior of the building. It was decided to place care and outpatient care areas on the 1 underground floor to avoid the presence of wards and rooms for patients on the entrance floor (Fig. 11) [17]. An independent entrance for outpatient services allowed access for external visitors from two different entrances. Thus, Hospital of Sant Joan Despi Doctor Moises Broggi is an example of a hospital building where the underground floor is entirely used as a treatment space rather than an auxiliary and technical area.
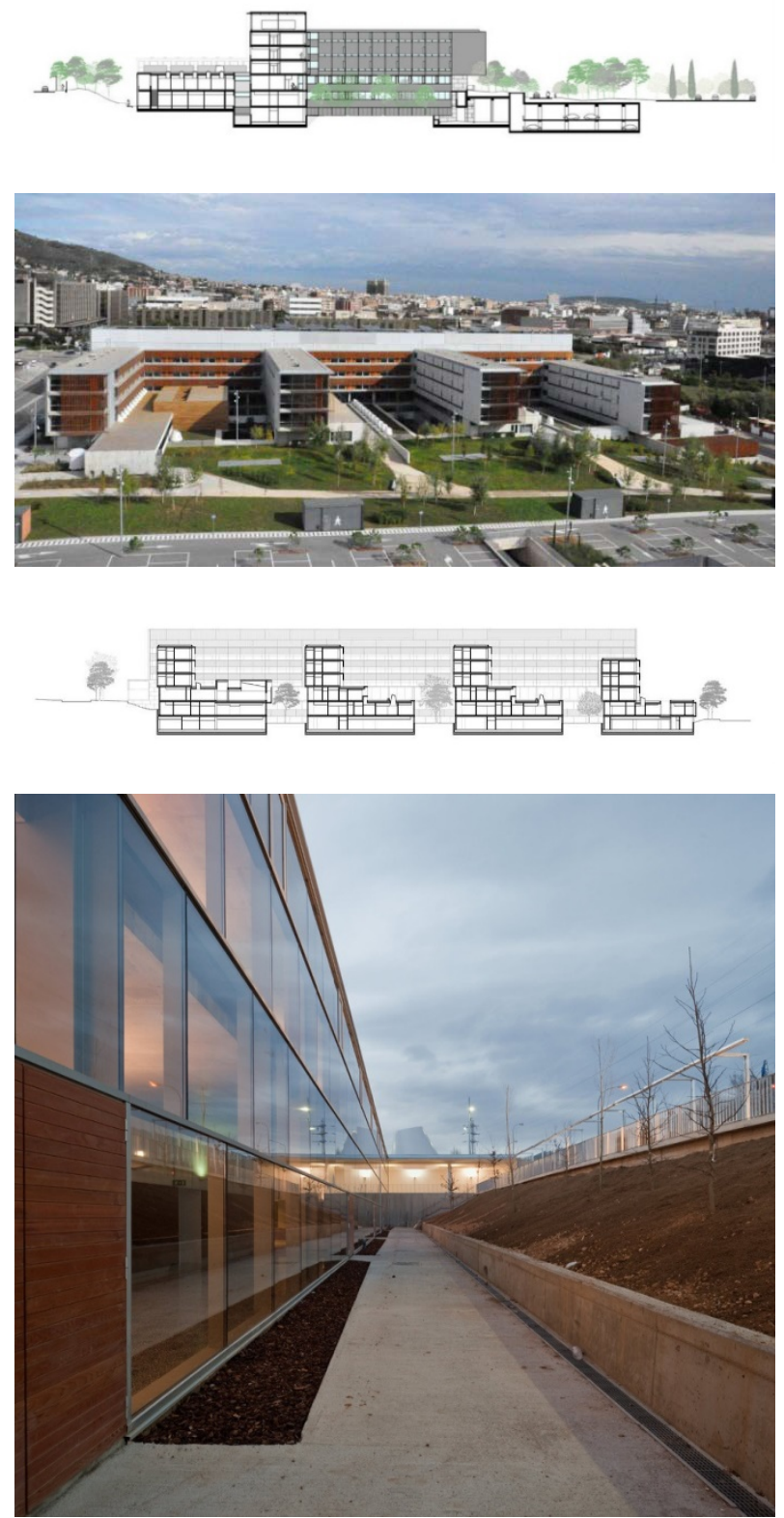

Figure 11. Hospital of Sant Joan Despi Doctor Moises Broggi, Sant Joan Despí, Spain

The potential use of underground space is also very clearly revealed in the Ulm Surgical Center project carried out by KSP Jürgen Engel Architekten in Ulm, Germany. Most of the hospital building is integrated into the landscape, thus actively using the underground space for medical purposes (operating rooms, intensive care units, clinics). The ground level part of the building is a 160-meter building that is extended horizontally above the ground and contains 235 beds in its treatment section (Fig. 12) [18]. To provide underground spaces with daylight, as well as to create a more natural and comfortable atmosphere of terrestrial spaces, the architects envisioned large courtyards in the project. Thus, the premises located on the underground level look and are perceived as a completely terrestrial environment.
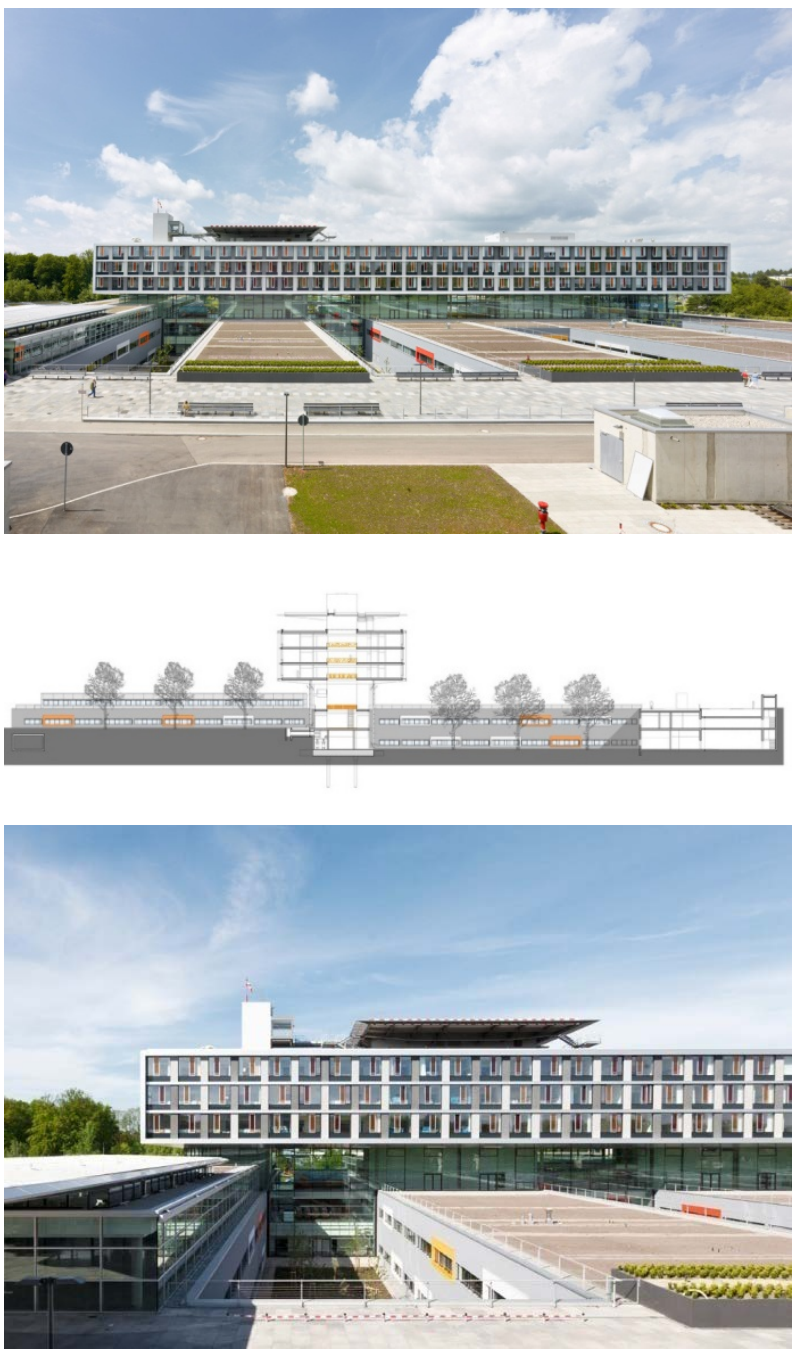

Figure 12. Ulm Surgical Center, Ulm, Germany

\section{Conclusions}

The architecture of healthcare institutions has changed significantly over the last decade and continues to improve. In most developed countries, architects gradually refuse from traditional approach to architectural design and construction of medical institutions. The conventional approach in most countries is to design hospitals solely as "above ground" buildings. This article shows that today architectural practice is being developed, architects 
explore new solutions (e.g. regarding natural light for underground space), and in some countries there are some hospital projects that are more innovative than others. And already today there is a rich experience of unique projects of hospitals, which are designed on the basis of sustainable development and ecological principles of design taking into account regional contexts and environmental potential. In this aspect, the direction of active use of positive opportunities for underground space integration in the design of healthcare facilities remains quite new and still uncommon. The location of various hospital functions on underground levels has many advantages: reduction of the perimeter of a building, which interacts with changing climatic conditions (which is especially important in countries with temperature fluctuations during the year); natural stable temperature in the room; facilitating the use of the potential of different types of heat pumps as a "green" means of increasing heat energy from alternative sources: soil, ambient air and groundwater; reduction of noise from the environment; possibility of using the area of the entire land plot with a significant underground extension, etc [19], [20], [21].

Of course, extensive use of underground space also has a number of limitations and disadvantages. In particular, there is a problem with high groundwater level in the area for the construction of healthcare facilities. But most of the other shortcomings, such as a lack of daylight in underground rooms, can be solved in quite interesting alternative ways (with the help of various types of atriums, "light wells", means that reflect sunlight, or a courtyard, etc.).

\section{REFERENCES}

[1] G. Golany. Urban Underground Space Design in China: Vernacular and Modern Practice, University of Delaware Press, Delaware, 1989.

[2] L. Osuská, R. Hela. The Impact of Different Aggregate Types and Its Composition on Resulting Concrete Properties Representing the Water Impermeability Level of Concrete for the Construction of White Boxes, Civil Engineering and Architecture, Vol. 8(2), 39-45, DOI: 10.13189/cea.2020.08 0201

[3] S. Ureel, R. Skaggs, K. Cato. Analysis and Solution for Fallout Repair and Tunneling in Sandy Soil Conditions for a Wine Cave in Southern California, Civil Engineering and Architecture, Vol. 6(5), 242-251, DOI: 10.13189/cea.2018. 060503

[4] K. Attarian, B. Safar Ali Najar. Vernacular and historic underground urban facilities and sustainability of cities case study: Infrastructures of Dezful, Journal of Cultural Heritage Management and Sustainable Development, Vol. 9(1), 2-23, https://doi.org/10.1108/JCHMSD-06-2017-0030

[5] I. Merylova, A. Perebityuk, V. Zadunay. L'influence de l'architecture sur l'état psychologique d'une personne, Construction, Architecture and Economics - 2020 International Context, Pridneprovsk State Academy of Civil Engineering and Architecture, 36-38.

[6] V. Vorobyov, I. Merylova. Predeterminations' Matrix in History of Architecture of the Future, Architectural Bulletin of KNUCA, Vol. 16, 360-367.

[7] S. Semerikov, S. Chukharev, S. Sakhno, A. Striuk, V. Osadchyi, V. Solovieva \& H. Danylchuk. Our sustainable coronavirus future, E3SWC, Vol. 166, 00001, DOI: 10.1051/e3sconf/202016600001,

https://www.e3s-conferences.org/articles/e3sconf/abs/2020/ 26/e3sconf_icsf2020_00001/e3sconf_icsf2020_00001.html

[8] I. V. Bulakh, O. Kozakova, M. Didichenko, O. Chala. Sustainable futures in the context of architectural design of hospitals, The International Conference on Sustainable Futures: Environmental, Technological, Social and Economic Matters (ICSF 2020), E3S Web of Conferences, Vol. 166. https://doi.org/10.1051/e3sconf/202016608001

[9] I. Bulakh, O. Chala, V. Divak. Dynamics of Architectural and Urban Planning Hospital Systems Evolution, Civil Engineering and Architecture, Vol. 8(4), 586-598, DOI: 10.13189/cea.2020.080423 http://www.hrpub.org/download/20200730/CEA23-148163 00.pdf

[10] I. V. Bulakh. Common Features of Architectural Design of the Medical Purpose Building, Science \& Technique, Vol. 18(4), 311-318. DOI: 10.21122/2227-1031-2019-18-4-311318 https://sat.bntu.by/jour/article/view/1990

[11] I. V. Bulakh. Urban Planning Organization and Development of Children's Medical Institutions in Ukraine, Journal of Regional and City Planning, Vol. 31, No. 1, 82-96. DOI: 10.5614/jpwk.2020.31.1.6 http://journals.itb.ac.id/ind ex.php/jpwk/article/view/12929/4655

[12] ArchDaily / Bundang Seoul National University Hospital, https://www.archdaily.com/462685/bundang-seoul-national -university-hospital-junglim-architecture

[13] ArchDaily / The Sieff Hospital, https://www.archdaily.com/ 788780/the-sieff-hospital-weinstein-vaadia-architects?ad_m edium=widget\&ad_name=recommendation

[14] ArchDaily / Pars Hospital, https://www.archdaily.com/7959 81/pars-hospital-new-wave-architecture?ad_medium=widg et\&ad_name=recommendation

[15] ArchDaily / New Hospital Tower Rush University Medical Center,

https://www.archdaily.com/443648/new-hospital-tower-rus h-university-medical-center-perkins-will?ad_medium=widg et\&ad_name=recommendation

[16] ArchDaily / Rey Juan Carlos Hospital,https://www.archdail y.com/238728/rey-juan-carlos-hospital-rafael-de-la-hoz?ad _medium=widget\&ad_name=recommendation

[17] ArchDaily / Hospital of Sant Joan Despi Doctor Moises Broggi,

https://www.archdaily.com/236028/hospital-of-sant-joan-de spi-doctor-moises-broggi-brullet-de-luna-arquitectes-pinear q?ad_medium=widget\&ad_name=recommendation

[18] ArchDaily / KSP Jürgen Engel Architekten, 
https://www.archdaily.com/254931/ulm-surgical-center-ksp -jurgen-engel-architekten

[19] I. V. Bulakh, O. Kozakova, M. Didichenko. The innovative trends in architecture and urban planning of health care institutions, International Journal of Innovative Technology and Exploring Engineering, Vol. 9(1), 317-323. DOI: 10.35940/ijitee.A4111.119119

https://www.ijitee.org/wp-content/uploads/papers/v9i1/A41 11119119.pdf

[20] I. V. Bulakh. Artistic and Aesthetic Formation and Evolution of Architectural and Urban Planning Space, Science and
Innovation, Vol. 15, No. 5(5), 57-66. DOI: 10.15407/scine15.05.057

http://scinn-eng.org.ua/archive/15\%285\%29/15\%285\%290 4

[21] G. Kovalska, I. Merylova, I. Bulakh. Urban improvement of comprehensive schools and out of school educational establishments in Ukraine, International Journal of Innovative Technology and Exploring Engineering, Vol. 8(12), 1765-1770. DOI: 10.35940/ijitee.L3229.1081219, https://www.ijitee.org/wp-content/uploads/papers/v8i12/L3 2291081219.pdf 